\title{
Conjugation, labelling and in vitro/in vivo assessment of an anti-VEGF monoclonal antibody labelled with niobium isotopes
}

\author{
A. de la Fuente ${ }^{1}$ V. Radchenko' ${ }^{1}$ T. Tsotakos ${ }^{2}$ - C. Tsoukalas ${ }^{2}$ M. Maravatou-Petsotas ${ }^{2}$ A. L. Harris ${ }^{3} \cdot$ U. Köster $^{4}$. \\ F. Rösch ${ }^{1} \cdot$ P. Bouziotis ${ }^{2}$
}

Received: 17 July 2018 / Published online: 15 November 2018

(C) Akadémiai Kiadó, Budapest, Hungary 2018

\begin{abstract}
Niobium-90 $\left({ }^{90} \mathrm{Nb}\right)$ is a positron emitting radionuclide that exhibits attractive characteristics for use in the design and synthesis of radioimmunoconjugates. In the current study we have investigated ${ }^{90} \mathrm{Nb}$ as a possible future isotope for immunoPET. Prior to ${ }^{90} \mathrm{Nb}$ in vivo studies, this paper describes in vitro and ex vivo studies using a Niobium-95 ( $\left.{ }^{95} \mathrm{Nb}\right)-\mathrm{monoclonal}$ antibody analogue. ${ }^{95} \mathrm{Nb}$ has a half-life of 35 days and is convenient for long-term studies. ${ }^{95} \mathrm{Nb}$-labelled bevacizumab was evaluated for early antiangiogenic tumor response assessment and the results were compared with other well established PET nuclides for immuno-PET. ${ }^{95} \mathrm{Nb}$ was quantitatively recovered (> 95\%) from irradiated natural $\mathrm{Zr}$ in a multistep separation. Bevacizumab was modified with the Df-Bz-NCS (Df) chelate and labelled with previously separated ${ }^{95} \mathrm{Nb}$. Stability of ${ }^{95} \mathrm{Nb}$-Df-bevacizumab was evaluated in saline and in human plasma over 7 days presenting $>96 \%$ and $>94 \%$ of intact product, respectively. Biodistribution ex vivo studies were performed on M165 tumor-bearing mice. ${ }^{95} \mathrm{Nb}$ was obtained in high purity $(99.999 \%)$ and high radioactivity concentration $(1.7 \mathrm{MBq} / \mu \mathrm{L})$ in a total volume of $200 \mu \mathrm{L}$ oxalic acid $(0.1 \mathrm{M})$, ready for labelling. Df-bevacizumab labelling was efficient $(>95 \%)$ and in vitro stability of ${ }^{95} \mathrm{Nb}-\mathrm{Df}$-bevacizumab was high. Ex vivo studies displayed good tumor-to-background ratios, optimum after 2 days p.i., after iv injection of $20 \mu \mathrm{g}$ of antibody per mouse. ${ }^{95} \mathrm{Nb}$ was successfully produced and purified from the irradiated target. Labeling of bevacizumab pre-modified with desferrioxamine was achieved in high yields. After in vitro stability of ${ }^{95} \mathrm{Nb}$-Df-bevacizumab was demonstrated, ex vivo biodistribution studies showed specific tumor uptake in M165 tumor-bearing mice. Consequently, in vivo studies with ${ }^{90} \mathrm{Nb}$-Df-bevacizumab and small animal PET are in preparation, and we expect that ${ }^{90} \mathrm{Nb}$-Df-conjugated antibodies will show potential for immuno-PET.
\end{abstract}

Keywords ${ }^{90 / 95} \mathrm{Nb} \cdot$ Bevacizumab $\cdot$ Labelling $\cdot$ VEGF $\cdot$ Biodistribution · Immuno-PET

\section{Introduction}

During the past decade a number of antiangiogenic agents such as sorafenib, an inhibitor of several tyrosine protein kinases, and ranibizumab, a monoclonal antibody that

* F. Rösch

frank.roesch@uni-mainz.de

1 Institut für Kernchemie, Johannes Gutenberg Universität Mainz, Fritz-Strassmann-Weg 2, 55128 Mainz, Germany

2 Institute of Nuclear and Radiological Sciences and Technology, Energy and Safety, N.C.S.R. "Demokritos", Athens, Greece

3 Weatherall Institute of Molecular Medicine, University of Oxford, Oxford, UK

4 Institut Laue-Langevin, Grenoble, France inhibits VEGF-A, have been US FDA approved. An important issue that needs our attention is the careful selection of patients that are most likely to respond to a specific antiangiogenic treatment. Nuclear imaging modalities have been explored as a possible way to screen patients for antiangiogenic therapy. Previous groups have demonstrated that radiolabeled bevacizumab accumulates in VEGF-A expressing tumors, and has thus been investigated as a potential SPECT and PET imaging agent for the selection of patients who are likely to benefi from antiangiogenic therapies [1-4]. More specifically, Nagengast et al. [1] were the first to report on the noninvasive measurement of VEGF-A levels in the tumor, with ${ }^{111} \mathrm{In}$ - and ${ }^{89} \mathrm{Zr}$-labeled bevacizumab. Nayak et al. [3] recently took a step further, by reporting on the radiolabelling of bevacizumab with ${ }^{86} \mathrm{Y}$ for PET imaging of VEGF-A tumor angiogenesis and as a surrogate marker 
for ${ }^{90} \mathrm{Y}$-based radioimmunotherapy (RIT), thus introducing a true theranostic agent, with distinct advantages over bevacizumab radiolabeled with ${ }^{111} \mathrm{In}$ and ${ }^{89} \mathrm{Zr}$, which have been proposed as surrogate markers for ${ }^{90} \mathrm{Y}$-based RIT. Another isotopic pair worth mentioning is the positron emitter ${ }^{64} \mathrm{Cu}$ $\left(t_{1 / 2}=12.7 \mathrm{~h}\right)$ and the $\beta^{-}$emitter ${ }^{67} \mathrm{Cu}\left(\left(t_{1 / 2}=2.6\right.\right.$ days $)$, which constitute an important theranostic pair in nuclear medicine.

Due to the slow pharmacokinetics of intact antibodies, positron-emitting radionuclides with long and medium-long half-lives are of interest for PET-imaging with antibodies; therefore ${ }^{68} \mathrm{Ga}$ and ${ }^{18} \mathrm{~F}$, which are common nuclides in routine PET imaging applications, are not suitable. ${ }^{90} \mathrm{Nb}$ is a promising candidate due its half-life of $14.6 \mathrm{~h}$ and low $\beta^{+}$ energy of $E_{\text {mean }}=0.662 \mathrm{MeV}$ [5]. In previous reports we have proposed ${ }^{90} \mathrm{Nb}$ as a promising candidate for application in immuno-PET [5-8] since its half-life of $14.6 \mathrm{~h}$ and a high positron branching of $53 \%$ may make ${ }^{90} \mathrm{Nb}$ an ideal candidate for application with antibody fragments and possibly intact monoclonal antibodies. Moreover, among the group of niobium isotopes we find the beta-emitter ${ }^{95} \mathrm{Nb}$, which could be exploited as a therapeutic isotope for molecules presenting slower pharmacokinetics, such as monoclonal antibodies, taking into account the presence of the high gamma ray energy (100\%) of $756 \mathrm{keV}$. These two isotopes of niobium could constitute the theranostic pair ${ }^{90} \mathrm{Nb} /{ }^{95} \mathrm{Nb}$, where the same biomolecule will be labeled with two different radioisotopes of the same element, thus affording both an imaging and a therapeutic agent with identical in vivo properties.

The humanized monoclonal antibody bevacizumab was the antibody chosen for the experiments as currently many studies are concentrating on the labelling of bevacizumab with radionuclides, in order to elucidateits in vivo behavior $[1-4,6,9]$. Bevacizumab plays a key role in angiogenesis, as it binds all vascular endothelial growth factor-A (VEGF-A) isoforms, preventing them from binding to receptors, thus blocking the biologic pathways induced after VEGF binding [10]. By blocking the receptors, the growth of vascular endothelial cells derived from arteries and veins, which are necessary to supply solid tumors with oxygen and nutrients, is highly diminished.

Because of the great variability of response to bevacizumab and lack of any predictive biomarkers [11], the search for sensitive technologies to monitor anti-angiogenic response in vivo is an ongoing one. It has previously been shown that radiolabelled bevacizumab can be used for in vivo VEGF visualization and quantifi due to its interaction with the larger isoforms of VEGF-A that are associated with the surface and/or the extracellular matrix [12]. Our research eff ts are focused on the development of ${ }^{90} \mathrm{Nb}$-bevacizumab as an example to demonstrate the suitability of imaging radiopharmaceuticals based on ${ }^{90} \mathrm{Nb}$.

In order to introduce ${ }^{90} \mathrm{Nb}$ as a novel positron emitter for immuno-PET, we have assessed the in vitro stability of bevacizumab radiolabeled with the long-lived niobium isotope ${ }^{95} \mathrm{Nb}$, as well as its cell binding capacity to breast cancer cells transfected with the VEGF-165 isoform. Furthermore, ex vivo biodistribution studies on tumor-bearing SCID mice were performed, in order to demonstrate the in vivo behavior of the radiolabeled antibody.

\section{Experimental}

\section{Materials}

Reagents were purchased from Sigma-Aldrich (Germany) and used without further purification, unless otherwise stated. Deionized water $\left(18 \mathrm{M} \Omega \mathrm{cm}^{-1}\right)$ and ultra pure $\mathrm{HCl}$ solution were used. No further special measures were taken regarding working under strict metal-free conditions. Bevacizumab (Avastin ${ }^{\circledR}$, Roche) was bought from Roche Ellas S. A. (Greece). For the purification of conjugated and labeled antibodies, PD-10 columns (GE Healthcare Life Science) were applied, for ion exchange separation Aminex A27, $15 \pm 2 \mu \mathrm{m}$ and AG1 $\times 8,200-400$ mesh anionic exchange resins and DOWEX 50 $\times 8,200-400$ mesh (BioRad) were used. For solid extraction, UTEVA ${ }^{\circledR}$ resin (Triskem Int., France) was applied.

The production yield, radionuclidic purity and separation yield of ${ }^{95} \mathrm{Nb}$ were determined by $\gamma$-ray spectroscopy using an Ortec HPGe detector system and Canberra Genie 2000 software. The dead time of the detector was always kept below $10 \%$. The detector was calibrated for efficiency at all positions with the certified standard solution QCY48, R6/50/38 (Amersham, UK).

VEGF165-transfected MDA MB 231 cells (M165) were cultured at safety level I in minimum essential medium (Eagle) with $2 \mathrm{mM}$ 1-glutamine in the presence of $10 \%$ fetal bovine serum, at $37{ }^{\circ} \mathrm{C}$ in a humidified $5 \% \mathrm{CO}_{2}$ incubator.

Labelling effi and stability of ${ }^{95} \mathrm{Nb}$-bevacizumab was monitored by instant thin layer chromatography (iTLC) and high performance liquid chromatography (HPLC). ITLC was performed on chromatography strips (Biodex, NY). As the mobile phase, $0.02 \mathrm{M}$ citrate buff ( $\mathrm{pH}$ 5.0) was used. HPLC monitoring was performed on a Waters HPLC system using a TSKgel G3000SWXL size exclusion column (TOSOH Bioscience, Germany). A mixture of $0.05 \mathrm{M}$ sodium phosphate and $0.15 \mathrm{M}$ sodium chloride $(\mathrm{pH} 6.8$ ) solution was used as the eluent, at a flow rate of $0.8 \mathrm{~mL} / \mathrm{min}$.

Statistical analysis was performed using the $t$ test. A $p$ value less than 0.05 was considered statistically significant.

\section{Production of ${ }^{95} \mathrm{Nb}$}

${ }^{95} \mathrm{Nb}\left(t^{1 / 2} 35\right.$ days) was employed for biodistribution experiments to cover longer periods of time. It was produced via 
the ${ }^{94} \mathrm{Zr}(n, \gamma) \rightarrow{ }^{95} \mathrm{Zr}\left(\beta^{-}, t{ }^{1 / 2} 64\right.$ days $) \rightarrow{ }^{95} \mathrm{Nb}$ reaction from 99.94\% pure zirconium foil (Product No. 00417, Alfa Aesar, USA). The foil contained $0.16 \mathrm{ppm} \mathrm{Nb}$. Neutron irradiation of $1.5 \times 10^{15} \mathrm{~s}^{-1} \mathrm{~cm}^{-2}$ and $1.0 \times 10^{15} \mathrm{~s}^{-1} \mathrm{~cm}^{-2}$ respectively was performed at the high flux reactor of Institut Laue-Langevin in Grenoble, France. A 7-day irradiation of $356.2 \mathrm{mg}$ of natural $\mathrm{Zr}$ produced more than $1.5 \mathrm{GBq}{ }^{95} \mathrm{Zr}$. The maximum daughter activity of $1 \mathrm{GBq}{ }^{95} \mathrm{Nb}$ generated from ${ }^{95} \mathrm{Zr}$ was obtained at $\sim 67$ days after end of irradiation The production of the radionuclides ${ }^{95} \mathrm{Zr} /{ }^{95} \mathrm{Nb}$ was monitored by gamma ray spectrometry, via emissions at $724.2 \mathrm{keV}$ (44.2\%) and $756.7 \mathrm{keV}(54.0 \%)$ for ${ }^{95} \mathrm{Zr}$, and at $765.8 \mathrm{keV}$ (100\%) for ${ }^{95} \mathrm{Nb}$.

\section{Separation and purification of n.c.a. ${ }^{95} \mathrm{Nb}$}

The separation/purification strategy, leading to high radioactive concentration of ${ }^{95} \mathrm{Nb}$, has been described elsewhere. Briefl, the irradiated zirconium target, dissolved in $21 \mathrm{M}$ hydrofl ic acid (HF) (extreme caution is required when working with or around HF) was passed through a cation exchange resin (DOWEX 50 $\times 8,100 \mathrm{mg}, 200-400 \mathrm{mesh}$, $10 \times 5 \mathrm{~mm}$ ) in $\mathrm{F}^{-}$form for the removal of colloids, unsolved target particles and possible trace contamination of $2^{+}$ and $3^{+}$metal cations, such as $\mathrm{Cu}^{2+}$ or $\mathrm{Fe}^{3+}$, from the target holder. The column was additionally washed with concentrated hydrofl ic acid $(1 \mathrm{~mL})$. This solution $(3 \mathrm{~mL})$ was transferred to an anion exchange column $(300 \mathrm{mg}$, $25 \times 5 \mathrm{~mm})$ filled with AG $1 \times 8$ resin (200-400 mesh) in the $\mathrm{F}^{-}$form. ${ }^{95} \mathrm{Nb}^{\mathrm{V}}$ remained on this resin and the bulk amount of $\mathrm{Zr}^{\mathrm{IV}}$ passed through. The column was washed with concentrated HF (4.5 mL) to elute traces of $\mathrm{Zr}^{\mathrm{IV}}$, while ${ }^{95} \mathrm{Nb}$ stays on the column. A small plastic column was filled with UTEVA resin $(150 \mu \mathrm{m}, 300 \mathrm{mg}, 25 \times 5 \mathrm{~mm})$, the aforementioned anion exchange column was directly connected with the UTEVA column and $4 \mathrm{~mL}$ of $0.3 \mathrm{M}$ oxalic acid/ $7.7 \mathrm{M}$ $\mathrm{HCl}$ were passed through both columns. The UTEVA column was next washed with $5 \mathrm{M} \mathrm{HCl}(5 \mathrm{~mL})$. Traces of $\mathrm{Zr}^{\mathrm{IV}}$ passed through the UTEVA, while ${ }^{95} \mathrm{Nb}^{\mathrm{V}}$ remains absorbed on the column. For elution of ${ }^{95} \mathrm{Nb}, 0.1 \mathrm{M}$ oxalic acid was applied. The column was washed with $200 \mu \mathrm{L}$ first and than ${ }^{95} \mathrm{Nb}$ was eluted with another $400 \mu \mathrm{L}$ of $0.1 \mathrm{M}$ oxalic acid. The whole process was monitored by gamma spectroscopy.

\section{Monoclonal antibody modification with Df-Bz-NCS}

Desferrioxamine (Df) has been shown to be an appropriate chelator for $\mathrm{Nb}$ [13]. Bevacizumab was pre-modifi with the bifunctional chelator Df-Bz-NCS following the protocol for ${ }^{89} \mathrm{Zr}$ labelling [14]. In short, a threefold molar excess of Df-Bz-NCS (in $20 \mu \mathrm{L}$ DMSO) was added to $5 \mathrm{mg}$ of the mab in $1 \mathrm{~mL} 0.1 \mathrm{M} \mathrm{NaHCO}_{3}$ buff, $\mathrm{pH} 9.0$, and incubated for $30 \mathrm{~min}$ at $37^{\circ} \mathrm{C}$. Non-conjugated chelator was separated by size exclusion chromatography (SEC) using a PD-10 column and saline as the eluent.

\section{Labelling of bevacizumab with ${ }^{95} \mathrm{Nb}$}

A purified ${ }^{95} \mathrm{Nb}$ fraction in $0.1 \mathrm{M}$ oxalic acid $(20-100 \mu \mathrm{L})$ was mixed with $300 \mu \mathrm{L}$ of $0.9 \%$ sodium chloride solution and then the mixture was adjusted to $\mathrm{pH}$ 6-7 with $0.1 \mathrm{M}$ $\mathrm{Na}_{2} \mathrm{CO}_{3}(50-60 \mu \mathrm{L})$. The modified mab (150-300 $\mu \mathrm{g}$, $120 \mu \mathrm{L}$ ) was then added to this mixture and the volume of the mixture was adjusted to $1 \mathrm{~mL}$ with normal saline. The mixture was incubated at room temperature for $60 \mathrm{~min}$. Finally, ${ }^{95} \mathrm{Nb}$-Df-Bz-NCS-bevacizumab was purified using a PD-10 column, with $0.9 \%$ sodium chloride solution as the mobile phase. Analysis of the product was monitored by ITLC (0.02 M citric acid/ACN, 90/10) and HPLC using a TSKgel G3000SWXL size exclusion column (TOSOH Bioscience, Germany), while a mixture of $0.05 \mathrm{M}$ sodium phosphate and $0.15 \mathrm{M}$ sodium chloride $(\mathrm{pH} 6.8)$ solution was used as the eluent, at a flow rate of $0.8 \mathrm{~mL} / \mathrm{min}$ for $60 \mathrm{~min}$.

\section{In vitro metabolic stability}

Metabolic stability of ${ }^{95} \mathrm{Nb}$-Df-bevacizumab was studied in normal saline at room temperature and in fresh human plasma at $37^{\circ} \mathrm{C}$. For preparation of human plasma, human blood was collected in heparinized polypropylene tubes and centrifuged at $5000 \mathrm{rpm}$ at $4{ }^{\circ} \mathrm{C}$ for $5 \mathrm{~min}$. The plasma was collected and incubated with ${ }^{95} \mathrm{Nb}$-Df-bevacizumab in threefold excess (300 $\mu \mathrm{L}$ plasma: $100 \mu \mathrm{L}$ radiotracer) at $37{ }^{\circ} \mathrm{C}$. Aliquots of the sample were withdrawn, treated with ethanol (2:1 EtOH/aliquot, v/v) and centrifuged, and the supernatant was analyzed by ITLC and HPLC.

\section{Immunoreactivity}

The immunoreactivity of radiolabelled bevacizumab was determined using a VEGF ELISA assay, as described by Collingride et al. [15]. Briefly, 96-well ELISA plates were coated with $100 \mu \mathrm{L}$ human VEGF165 (5 $\mu \mathrm{g} / \mathrm{mL}$, R\&D Systems; Oxfordshire, United Kingdom) overnight in bicarbonate coating buffer $\left(15 \mathrm{mM} \mathrm{Na}_{2} \mathrm{CO}_{3}, 35 \mathrm{mM} \mathrm{NaHCO}{ }_{3}, \mathrm{pH}\right.$ 9.6) at $4{ }^{\circ} \mathrm{C}$. As a next step, wells were blocked with $100 \mu \mathrm{L}$ of $1 \%$ BSA in PBS. The wells were then washed three times with PBS and $0.1 \%$ Tween 80 . Radiolabelled bevacizumab was diluted to $10 \mathrm{ng} / \mathrm{mL}$, added to the wells $(100 \mu \mathrm{L})$ and allowed to bind for $2 \mathrm{~h}$ at room temperature. After incubation, the unbound antibody was removed, the wells were washed three times with PBS and $0.1 \%$ Tween 80 , and the bound antibody was solubilized with $0.2 \mathrm{M} \mathrm{NaOH}$. The total radioactivity added to each well and the radioactivity from bound antibody was measured on a multisample $\gamma$-counter system Packard Minaxi 5500 equipped with a 3"' NaI (Tl) 
crystal. Immunoreactivity of the antibody was calculated as bound counts $\times 100 /$ total counts. Experiments were repeated three times.

\section{Cell binding experiments}

For the cell binding experiments, MDA MB 231 human breast cancer cells stably transfected with the VEGF-165 isoform (M165 cells) were used. These M165 cells overexpressing VEGF-165 were cultured in DMEM supplemented by $10 \%(\mathrm{v} / \mathrm{v})$ fetal bovine serum (FBS) $100 \mathrm{U} / \mathrm{mL}$ penicillin and $100 \mu \mathrm{g} / \mathrm{mL}$ streptomycin. Cells were kept in a controlled humidified atmosphere containing $5 \% \mathrm{CO}_{2}$ at $37^{\circ} \mathrm{C}$.

On the previous day of the experiment, cells were seeded in 24-well plates and grown to confl . For the binding experiment, increasing concentrations of the labelled antibody (2.0, 4.0, and $10.0 \mathrm{nM})$ were added to each well. Triplicates of each concentration were incubated at $37{ }^{\circ} \mathrm{C}$ for $60 \mathrm{~min}$. In order to assess binding specifi , M165 cells in some of the wells were pretreated with an excess of unlabeled bevacizumab $(125 \mu \mathrm{g})$. The supernatant was then removed, the cells were washed three times with ice-cold PBS, and the bound antibody was solubilized with $0.2 \mathrm{M}$ $\mathrm{NaOH}$. The total radioactivity added to each well and radioactivity from bound antibodies was measured in a gamma counter.

\section{Biodistribution studies}

All animal experiments were performed in compliance with EC Directive 86/609 and its implementation in national legislation (updated version EL 56/2013). Female athymic SCID mice (average weight $20 \mathrm{~g}$, 5 weeks) were obtained from the breeding facilities of the Institute of Biology of the NCSR "Demokritos". The SCID mice were inoculated subcutaneously into the right front leg with M165 cells $\left(1 \times 10^{7}\right.$ cells/animal $)$ in $100 \mu \mathrm{L}$ fetal bovine serumfree medium. When tumors reached a size of $0.2-1 \mathrm{~g}$ (i.e. 10-15 days), biodistribution studies were performed.

Tumor-bearing mice were injected with $100 \mu \mathrm{L}$ of ${ }^{95} \mathrm{Nb}$ Df-bevacizumab [(270 kBq/20 $\mu \mathrm{g}$ bevacizumab or $2.03 \mathrm{TBq} /$ $\mathrm{mmol}(54.83 \mathrm{mCi} / \mathrm{mmol})]$ via the tail vein. Groups of three animals were sacrificed at 1,2 and 4 days post-injection.

To prove specifi binding of the ${ }^{95} \mathrm{Nb}$-Df-bevacizumab to the tumor, blocking experiments were performed in the tumor-bearing mice. A group of animals was treated with 125 -fold excess of the cold bevacizumab $(2500 \mu \mathrm{g} / 100 \mu \mathrm{L})$ and after $24 \mathrm{~h}$, these animals were injected with $270 \mathrm{kBq} / 20 \mu \mathrm{g}$ [2.03 TBq/mmol $(54.83 \mathrm{mCi} / \mathrm{mmol})]{ }^{95} \mathrm{Nb}-$ Df-bevacizumab and sacrified at 4 days after injection of the radiolabelled antibody.

Tumors, tissues and organs (blood, heart, liver, stomach, intestines, spleen, muscle, lungs, pancreas, muscle and bones) were excised, blotted dry and weighed. Samples were counted in a gamma counter (NaI gamma counter, Packard). Standards were prepared from the injected material and were counted each time simultaneously with the tissues excised, allowing for calculations to be corrected for physical decay of the radioisotope. Radiolabelled antibody distribution over time was expressed as injected dose per gram $(\% \mathrm{ID} / \mathrm{g})$.

\section{Results}

\section{Separation and purification of no-carrier-added ${ }^{95} \mathrm{Nb}$}

The overall separation proceeds with a yield of $95-98 \%$ of ${ }^{95} \mathrm{Nb}$, collected in $400 \mu \mathrm{L} 0.1 \mathrm{M}$ oxalic acid with the whole separation procedure lasting less than $1 \mathrm{~h}$. Decontamination after UTEVA purification is $3 \times 10^{8}$ which equals to $0.77 \mathrm{ng}$ of zirconium present in the fi fraction for a portion of $260 \mathrm{mg}$ zirconium target.

\section{Preparation of ${ }^{95} \mathrm{Nb}$-labeled Df-Bz-NCS-bevacizumab}

Labelling kinetics indicate a yield of $\geq 80 \%$ already at $15 \mathrm{~min}$, while the final labelling yield with ${ }^{95} \mathrm{Nb}$ was $\geq 95 \%$ (96\% ITLC, 95\% HPLC) after $1 \mathrm{~h}$ (Fig. 1). After SEC separation on a PD-10 column, the ${ }^{95} \mathrm{Nb}$-Df-bevacizumab had a radiochemical purity of $99 \%$. The specific activity was 2.03 $\mathrm{TBq} / \mathrm{mmol}(54.83 \mathrm{Ci} / \mathrm{mmol})$.

\section{In vitro stability}

After 7 days of incubation of ${ }^{95} \mathrm{Nb}$-Df-bevacizumab in $\mathrm{NaCl} 0.9 \%$ solution at $37{ }^{\circ} \mathrm{C}$ and $\mathrm{RT}$, radiochemical purity

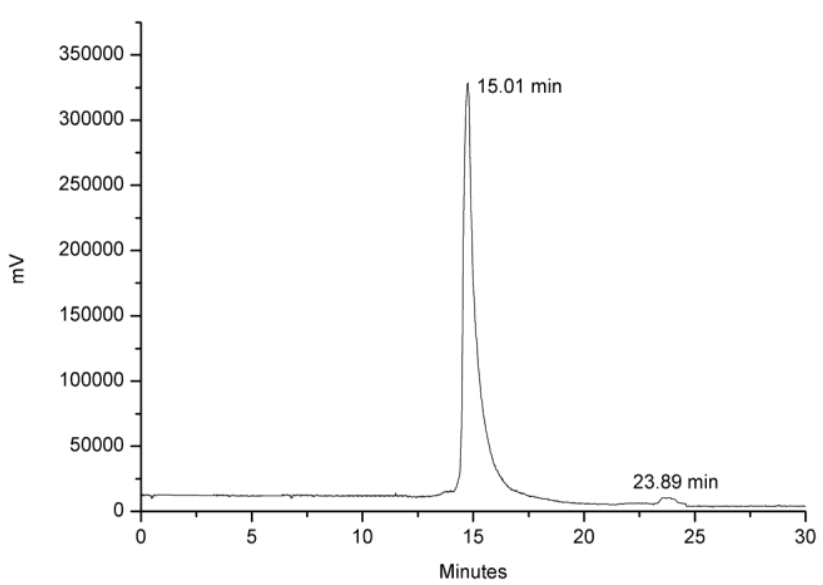

Fig. 1 HPLC radiochromatogram ${ }^{95} \mathrm{Nb}$-bevacizumab (15.01 min). The small peak at 23.89 min represents uncomplexed ${ }^{95} \mathrm{Nb}$ 
of the final product $\geq 95 \%$ (99\% HPLC, 97\% ITLC) was still detected. Stability testing in fresh human plasma at $37{ }^{\circ} \mathrm{C}$ showed slightly higher product degradation. After 3 days of incubation $\geq 94 \%$ (97\% HPLC, 94\% ITLC) of labelled product was available, while at 7 days $\geq 86 \%$ (89\% HPLC, $86 \%$ ITLC) of the product was still intact.

\section{Immunoreactivity and cell binding experiments}

An immunoreactivity assay was performed to ascertain the biological integrity of the labeled ${ }^{95} \mathrm{Nb}$-Df-bevacizumab,

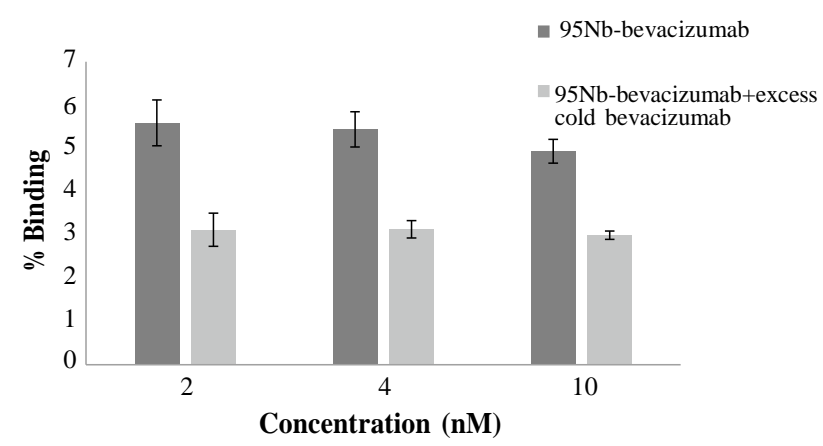

Fig. 2 In vitro cell binding studies of increasing concentrations of ${ }^{95} \mathrm{Nb}$-Df-bevacizumab on M165 cells and showed that the immunoreactivity of the radiolabeled antibody was $47.98 \pm 1.62 \%$.

In vitro binding studies performed on M165 cells showed a low overall percentage of ${ }^{95} \mathrm{Nb}$-Df-bevacizumab binding, compared to the initially added activity, which was diminished when the cells were pretreated with an excess of cold bevacizumab (Fig. 2). We are thus led to the conclusion that the low percentage of binding of ${ }^{95} \mathrm{Nb}$-Df-bevacizumab can be attributed to binding both to the secreted VEGF-165, but also to the cell-associated VEGF-165.

\section{Biodistribution}

Biodistribution of ${ }^{95} \mathrm{Nb}$-Df-bevacizumab, at an injected dose of $270 \mathrm{kBq} / 20 \mu \mathrm{g}[2.03 \mathrm{TBq} / \mathrm{mmol}(54.83 \mathrm{mCi} / \mathrm{mmol})]$ per mouse was performed in tumor-bearing mice (Fig. 3).

At all time-points, the levels of radiotracer in most tissues (blood, liver, spleen, lungs, heart, stomach, intestines and pancreas) were less than those in the tumor. Tumor uptake showed a decreasing pattern in time $(9.42 \pm 3.75 \% \mathrm{ID} / \mathrm{g}$ and $1.21 \pm 0.38 \% \mathrm{ID} / \mathrm{g}$ at 1 and 4 days p.i., respectively), however the tumor-to-blood ratios increased from 1 to 4 days p.i. ( $3.53 \pm 0.21$ and $5.35 \pm 0.66$, respectively), cf. Table 1 .

Specificity of tumor targeting was assessed by injecting tumor-bearing mice with an excess of unlabelled bevacizumab, also shown in Fig. 3. When mice were given unlabeled bevacizumab 1 day prior to ${ }^{95} \mathrm{Nb}$-Df-bevacizumab and
Fig.3 Biodistribution of ${ }^{95} \mathrm{Nb}$-Df-bevacizumab $(270 \mathrm{kBq} / 20 \mu \mathrm{g} /$ mouse, [2.03 $\mathrm{TBq} / \mathrm{mmol}(54.83 \mathrm{Ci} / \mathrm{mmol})]$ in tumor-bearing mice

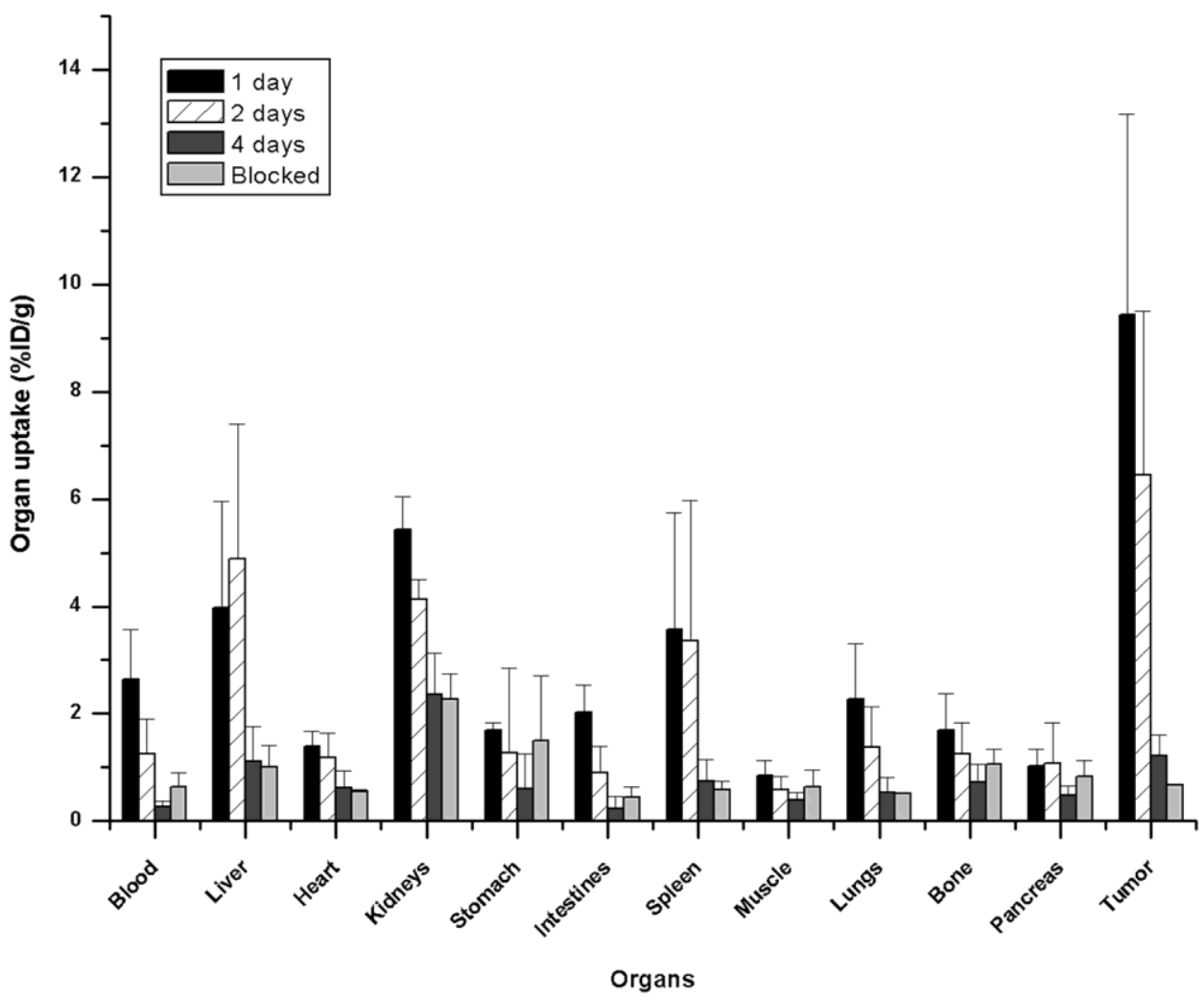


Table 1 Tumor-to-blood ratios of ${ }^{95} \mathrm{Nb}$-Df-bevacizumab at 1, 2 and 4 days p.i.

\begin{tabular}{llll}
\hline 1 day & 2 days & 4 days & 4-day blocking \\
\hline $3.53 \pm 0.21$ & $5.15 \pm 0.28$ & $5.35 \pm 0.66$ & $1.17 \pm 0.42$ \\
\hline
\end{tabular}

sacrificed 4 days later, the $\% \mathrm{ID} / \mathrm{g}$ in the tumor decreased by $\sim 50 \%$, compared with unchallenged mice $(0.68 \pm 0.02 \% \mathrm{ID} / \mathrm{g}$ vs. $1.21 \pm 0.38 \% \mathrm{ID} / \mathrm{g}$ respectively). The $\% \mathrm{ID} / \mathrm{g}$ for the other tissues did not decrease, on the contrary, ${ }^{95} \mathrm{Nb}$-Df-bevacizumab showed a slight increase after pretreatment with unlabeled bevacizumab.

\section{Discussion}

Our focus is on the development of a novel PET imaging agent, namely ${ }^{90} \mathrm{Nb}$-Df-bevacizumab, by investigating the radiolabelling and in vitro/in vivo characteristics of bevacizumab radiolabeled with ${ }^{95} \mathrm{Nb}$, a convenient alternative for longer-term ex vivo biodistribution studies, due to its longer half-life ( $t^{1 / 2} 35$ days) and its convenient, lower-cost production (reactor-based production).

Immunoreactivity studies showed adequate VEGF binding of ${ }^{95} \mathrm{Nb}$-Df-bevacizumab, thus proving that bevacizumab retained its immunoreactivity post-labelling. The results acquired for ${ }^{95} \mathrm{Nb}$-Df-bevacizumab were comparable to other reported immunoreactivity data for radiolabeled bevacizumab [1-3]. Cell binding studies on M165 cells showed that ${ }^{95} \mathrm{Nb}$-Df-bevacizumab bound to the cells, and that binding was decreased when an excess of bevacizumab was added to the cells prior to the addition of the radiotracer.

${ }^{95} \mathrm{Nb}$-Df-bevacizumab remains intact over a long period of time. A biodistribution study was performed in tumorbearing mice injected at 1,2 and 4 days p.i. $[270 \mathrm{kBq} / 20 \mu \mathrm{g}$ bevacizumab/mouse, $2.03 \mathrm{TBq} / \mathrm{mmol}(54.83 \mathrm{Ci} / \mathrm{mmol})]$. A dramatic decrease in blood pool activity was observed up to 4 days p.i. $(2.63 \pm 0.93 \% \mathrm{ID} / \mathrm{g}$ at 1 day vs. $0.26 \pm 0.11 \% \mathrm{ID} / \mathrm{g}$ at 4 days). Maximum tumor accumulation was observed at 1 day p.i., with $\sim 68 \%$ of the radioactivity still present in the tumor at 2 days p.i. $(9.42 \pm 3.75 \% \mathrm{ID} / \mathrm{g}$ vs. $6.44 \pm 3.07 \%$ $\mathrm{ID} / \mathrm{g}$ ). While tumor uptake further decreased at 4 days p.i., tumor-to-blood ratios increased from 1 to 4 days p.i. $(3.53 \pm 0.21$ vs. $5.35 \pm 0.66)$. In all cases, low bone uptake was observed over time, which demonstrates the stability of the ${ }^{95} \mathrm{Nb}-\mathrm{Df}$ complex.

Tumor uptake of ${ }^{95} \mathrm{Nb}$-Df-bevacizumab was lower than that observed with bevacizumab labelled with other isotopes $[1-4,6]$ and this may be due to the differences in the available target for the antibody, namely the VEGF-165 isoform. While bevacizumab has high binding affinity to all VEGF-A isoforms, which are found in the extracellular matrix (ECM), the M165 cell line used in our experiments overexpresses the VEGF-165 isoform, which is partly cell- and ECM-associated and partly secreted from the cells. Therefore, binding of ${ }^{95} \mathrm{Nb}$-Df-bevacizumab to both cell- and ECM-associated as well as secreted VEGF may be the reason for the observed washout from the tumor [16]. Finally, the use of $20 \mu \mathrm{g}$ of ${ }^{95} \mathrm{Nb}$-Df-bevacizumab per mouse for biodistribution studies may have resulted in accelerated and increased clearance of the radiotracer in the absence of $\mathrm{IgG}$ production by nude mice [17]. Another reason that can explain the relatively low uptake of the ${ }^{95} \mathrm{Nb}$-labelled $\mathrm{Ab}$ into the tumor may be the relatively low specifi activity of the product and correspondingly high amount of injected $\mathrm{Ab}(20 \mu \mathrm{g})$. It has been reported that there is there is an inverse relationship between the amount of Ab injected into a mouse and tumor uptake [4]. The relatively high amount of $20 \mu \mathrm{g}$ injected to the mice may also explain why the tumor concentration decreases over time, as it is being displaced by unlabeled $\mathrm{Ab}$. Nonetheless, the tumor-to-blood ratios of our experiments are higher than those that have been shown by other groups [1, 3, 4, 18-20].

The preinjection of an excess of unlabeled bevacizumab prior to ${ }^{95} \mathrm{Nb}$-Df-Bevacizumab resulted in a signifi reduction in tumor uptake $(1.22 \pm 0.38 \% \mathrm{ID} / \mathrm{g}$ vs. $1.68 \pm 0.02 \% \mathrm{ID} / \mathrm{g}, p<0.037$ ), leading to the conclusion that ${ }^{95} \mathrm{Nb}$-Df-bevacizumab binds specifically to VEGF in vivo. A slight increase in radiotracer uptake in the normal tissues was also observed, which is probably attributable to the fact that unlabeled bevacizumab blocks the available VEGF binding sites in tumors, thus leading to an excess of ${ }^{95} \mathrm{Nb}$ Df-bevacizumab in the circulation. This is also demonstrated in ${ }^{95} \mathrm{Nb}$-Df-bevacizumab blood levels of mice injected pretreated with excess antibody, which are significantly higher than in those without excess antibody $(0.64 \pm 0.24 \% \mathrm{ID} / \mathrm{g}$ vs. $0.26 \pm 0.12 \% \mathrm{ID} / \mathrm{g}$, respectively, $p<0.05)[3,16]$.

Obtained data clearly showed excellent labelling and stability of ${ }^{95} \mathrm{Nb}$-Df- bevacizumab in vitro and in vivo. The ${ }^{*} \mathrm{Nb} / \mathrm{Zr}$ separation chemistry developed should allow the synthesis of ${ }^{90} \mathrm{Nb}$-Df-bevacizumab following the ${ }^{90} \mathrm{Zr}(\mathrm{p}, \mathrm{n})$ production process at high specific activity of $>100 \mathrm{MBq} /$ $\mathrm{mg}$ mab. This PET tracer will be used to reproduce the promising results shown here with ${ }^{95} \mathrm{Nb}$-Df-bevacizumab and to further validate its potential for application in immuno-PET. In conclusion, we believe that ${ }^{90} \mathrm{Nb}$-Df-bevacizumab would be a valuable tool for the selection of patients most likely to benefit from antiangiogenic therapies targeting VEGF-A. Further work has been planned on the possible application of ${ }^{90 / 95} \mathrm{Nb}$-Df-bevacizumab as a theranostic radioimmunodiagnostic/radioimmunotherapeutic pair.

Acknowledgements The authors gratefully acknowledge financial support from the COST Actions TD1004 (Theranostics Imaging and Therapy: An Action to Develop Novel Nanosized Systems 
for Imaging-Guided Drug Delivery) and D38 (Metal-Based Systems for Molecular Imaging Applications), the Programme for the Promotion of the Exchange and Scientific Cooperation between Greece and Germany IKYDA 2013 (Contract No. 205), the People Programme (Marie Curie Actions) of the European Union's seventh Framework Programme (FP7/2007-2013) under REA Grant Agreement No. PITNGA-2012-317019 'Trace'n Treat', and the Deutsche Forschungsgemeinschaft (DFG) under Grant DFG Ro 985/40 - 1. Acknowledgements are also due to Mr. Stavros Xanthopoulos, for excellent technical assistance. We also acknowledge the reactor teams of BER2 Berlin and TRIGA Mainz where irradiations for preparatory experiments had been performed and the reactor team of ILL Grenoble for producing the ${ }^{95} \mathrm{Zr} /{ }^{95} \mathrm{Nb}$ activity used in the present work.

\section{References}

1. Nagengast WB, de Vries EG, Hospers GA, Mulder NH, de Jong JR, Hollema $\mathrm{H}$ et al (2007) In vivo VEGF imaging with radiolabeled bevacizumab in a human ovarian tumor xenograft. $\mathrm{J}$ Nucl Med 48:1313

2. Nagengast WB, de Korte MA, Oude Munnink TH, Timmer-Bosscha H, den Dunnen WF, Hollema H et al (2010) ${ }^{89} \mathrm{Zr}$-bevacizumab PET of early antiangiogenic tumor response to treatment with HSP90 inhibitor NVP-AUY922. J Nucl Med 51:761-767

3. Nayak TK, Garmestani K, Baidoo KE, Milenic DE, Brechbiel MW (2011) PET imaging of tumor angiogenesis in mice with Vegf-A-targeted ${ }^{86} \mathrm{Y}$-chx-a"-dtpa-bevacizumab. Int J Cancer 128:920

4. Stollman TH, Scheer MGW, Leenders WPJ (2008) Specific imaging of VEGF-A expression with radiolabeled anti-VEGF monoclonal antibody. Int J Cancer 122:2310

5. Radchenko V, Hauser H, Eisenhut M, Vugts JD, van Dongen GA, Roesch F (2012) 90Nb: a potential PET nuclide: production and labeling of monoclonal antibodies. Radiochim Acta 100:857

6. Radchenko V, Bouziotis P, Tsotakos T, Paravatou-Petsotas M, de la Fuente A, Loudos G et al (2016) Labeling and preliminary in vivo assessment of niobium-labeled radioactive species: a proof-of-concept study. Nucl Med Biol 43:280

7. Busse S, Rösch F, Qaim SM (2002) Cross section data for the production of the positron emitting niobium isotope $90 \mathrm{Nb}$ via the ${ }^{90} \mathrm{Zr}(\mathrm{p}, \mathrm{n})$-reaction. Radiochim Acta 90:1-5

8. Radchenko V, Filosofov DV, Bochko OK, Lebedev NA, Rakhimov A, Aksenov NV, Bozhikov GA, Roesch F (2014) Separation of ${ }^{90} \mathrm{Nb}$ from zirconium target for application in immuno-PET. Radiochim Acta 102(5):433-443.
9. Busse S, Brockmann J, Roesch F (2002) Radiochemical separation of no-carrier-added radioniobium from zirconium targets for application of ${ }^{90} \mathrm{Nb}$-labelled compounds. Radiochim Acta 90:411

10. Ferrara N, Hillan KJ, Novotny W (2005) Bevacizumab (Avastin), a humanized anti-VEGF monoclonal antibody for cancer therapy. Biochem Biophy Res Commun 333:328

11. Jayson GC, Kerbel R, Ellis LM, Harris AL (2016) Antiangiogenic therapy in oncology: current status and future directions. Lancet 388:518-529

12. Stollman TH, Scheer MG, Franssen GM, Verrijp KN, Oyen WJ, Ruers TJ et al (2009) Tumor accumulation of radiolabeled bevacizumab due to targeting of cell- and matrix-associated VEGF-A isoforms. Cancer Biother Radiopharm 24:p195

13. Radchenko V, Busse S, Roesch F (2014) Desferrioxamine as an appropriate chelator for ${ }^{90} \mathrm{Nb}$ : comparison of its complexation properties for M-Df-Octreotide ( $\mathrm{M}=\mathrm{TNb}, \mathrm{Fe}, \mathrm{Ga}, \mathrm{Zr}$ ). Nucl Med Biol 41:p721

14. Vosjan MJ, Perk LR, Visser GW, Budde M, Jurek P, Kiefer GE, van Dongen GA (2010) Conjugation and radiolabeling of monoclonal antibodies with zirconium-89 for PET imaging using the bifunctional chelate p-isothiocyanatobenzyl-desferrioxamine. Nat Protoc 5:p739

15. Collingridge DR, Carroll VA, Glaser M, Agoagye EO, Osman S, Hutchinson OC, Barthel $\mathrm{H}$ et al (2002) The development of $\left[{ }^{124} \mathrm{I}\right]$ iodinated-VG76e: a novel tracer for imaging vascular endothelial growth factor in vivo using positron emission tomography. Cancer Res 62:p5912

16. Park JE, Keller GA, Ferrara N (1993) The Vascular endothelial growth factor (VEGF) isoforms: diff ential deposition into the subepithelial extracellular matrix and bioactivity of extracellular matrix-bound VEGF. Mol Biol Cell 4:p1317

17. Sharkey RM, Natale A, Goldenberg DM, Mattes MJ (1991) Rapid blood clearance of immunoglobulin G2a and immunoglobulin G2b in nude mice. Cancer Res 51:p3102

18. Paudyal P, Paudyal B, Hanaoka H, Oriuchi N, Iida Y, Yoshioka $\mathrm{H}$ et al (2010) Imaging and biodistribution of Her2/neu expression in non-small cell lung cancer xenografts with ${ }^{64} \mathrm{Cu}$-labeled trastuzumab PET. Cancer Sci 101(4):1045-1050

19. Kameswarah M, Pandey U, Gamre N, Vimalnath KV, Sarma HD, Dash A (2016) Evaluation of ${ }^{177}$ Lu-CHX-A"'-DTPA-Bevacizumab as a radioimmunotherapy agent targeting VEGF expressing cancers. Appl Radiat Isot 114:p196

20. Camacho X, Garcia MF, Calzada V, Fernandez M, Chabalgoity JA, Moreno $\mathrm{M}$ et al (2013) [ $\left.{ }^{99 \mathrm{~m}} \mathrm{Tc}(\mathrm{CO}) 3\right]$-radiolabeled bevacizumab: in vitro and in vivo evaluation in a melanoma model. Oncology 84:p200 